\title{
AUTORIA E CONTRADIÇÃO NO PROCESSO DISCURSIVO DE REFORMULAÇÃO DE LIVROS
}

\section{AUTHORSHIP AND CONTRADICTION IN THE DISCURSIVE PROCESS OF BOOKS REFORMULATION}

\author{
Adriana Pozzani de La Vielle e Silva ${ }^{1}$ \\ UFRGS - Universidade Federal do Rio Grande do Sul
}

\begin{abstract}
RESUMO: Como pensar discursivamente a edição revista e seu processo de escrita? A Teoria da Análise do Discurso (tal como desenvolvida especialmente por Pêcheux, Orlandi e Indursky) sustenta esta discussão a respeito do processo discursivo de reformulação de livros e, por aí, acerca da reformulação de domínios de saber. Interessando-nos as reconfigurações científicas internas, observamos o trabalho de autoria na materialidade linguístico-histórica de pares de edições, a fim de examinar, de um lado, as relações entre o sujeito-autor e as duas versões de um livro seu, e, de outro lado, o estatuto discursivo da edição revista.
\end{abstract}

PALAVRAS-CHAVE: Autoria; Formação Discursiva; Identidade

ABSTRACT: How can we discursively think about the revised edition and its writing? Discourse Analysis Theory (as it is specially developed by Pêcheux, Orlandi and Indursky) sustains this discussion about the discursive process of books reformulation and, by this way, about the reformulation of knowledge domains. Once we are interested on scientific internal reconfigurations, we observe the authorship work on the linguistic-historical materiality of pairs of editions, in order to examine, on the one hand, the relations established between the subject-author and the two versions of a book of him, and, on the other hand, the discursive statute of the revised edition.

KEYWORDS: Authorship; Discursive Formation; Identity

\section{Considerações iniciais}

Este artigo foi elaborado a partir de minha Dissertação de Mestrado - qual seja, "Entretextualidade nas fronteiras do enunciável: um olhar sobre o processo discursivo de reformulação de livros" (cf. Silva, 2009) -, tendo a mesma, por sua vez, sido produzida sob orientação da Prof. ${ }^{a}$ Dr. ${ }^{a}$ Freda Indursky (PPGLet-UFRGS). Desse Trabalho, efetuado no quadro da Análise do Discurso (tal como desenvolvida especialmente por Pêcheux, Orlandi e Indursky), serão adaptadas à natureza do presente escrito algumas considerações em torno do eixo discurso-autoria-identidade, com vistas a uma discussão sobre a reformulação de livros. Assim, toma-se como objeto analítico o processo discursivo de reformulação de livros, isto é, o caso de reformulações autorais que, efetuadas em livros impressos basilares,

\footnotetext{
${ }^{1}$ Mestre em Estudos da Linguagem pela Universidade Federal do Rio Grande do Sul (UFRGS) e Professora de Língua Portuguesa.
} 
incidem sobre a metalinguagem ao ressignificar conceitos fundantes e implicam um redimensionamento de determinadas parcelas do saber próprio à ciência no interior da qual o sujeito-autor do livro se situa. Para o presente artigo, em especial, trata-se de observar Prefácios e Notas do Autor sobre a edição revista uma vez colocadas as seguintes questões: como pensar discursivamente a edição revista e seu processo de escrita? Está-se diante de um livro cuja identidade é ambígua? Qual a relação do sujeito-autor-revisor com as distintas versões de um livro seu? Objetivamos analisar, basicamente, o funcionamento da autoria e o estatuto discursivo da edição revista. Tal objetivo conduz, evidentemente, à tentativa de capturar os modos pelos quais o sujeito se relaciona com saberes da formação discursiva (campo de conhecimento) no interior da qual se inscreve.

Pensar a reformulação de campos de saber por meio de uma análise da reformulação de livros coloca a necessidade de inscrever a edição revista nas condições sóciohistóricas que a instauram e que determinam os modos de apropriação/reprodução/transformação de saberes do campo no qual ela se constitui e do qual ela, de certa maneira, decorre. Ora, num determinado momento, o texto de uma dada edição passa a já não servir, e até mesmo a ser inapropriado, daí resultando então a necessidade de "atualizar" o livro, de reestruturá-lo; e tal situação cria um confronto na hegemonia de saberes que perdem seu posto hierárquico em prol da hegemonia da "nova" parcela de saberes. Pensemos sobre essa questão a partir de Zandwais (2005, p.84), que diz o seguinte: "Se não se pode julgar o espírito de uma época somente pelo que ela pensa de si mesma", visto que "cada época está impregnada de suas verdades, e, portanto, de suas formas de inclusão de saberes em torno de como se legitimam determinadas práticas sociais/discursivas em detrimento de outras", então é preciso, ao menos, apreender suas relações de contradição, a fim de que se possa investigar sob que condições saberes "tornam-se hegemônicos ou legitimados superestruturalmente e passam a exercer determinadas formas de controle sobre outros." Cumpre, pois, investigar as práticas discursivas que instauram a contradição nas formações discursivas.

\section{Pressupostos teóricos para o exame da reformulação de livros}

Ao abordar a elaboração de conhecimentos científicos enquanto um processo discursivo, Pêcheux (1975/1988) afirma que a produção histórica desses conhecimentos não resulta de um mero ato de inovar mentalidades ou de uma criação imaginativa do homem; ela é efeito de todo um processo histórico. E assim, os conceitos de uma dada ciência não possuem exatamente um sentido, mas antes uma "função em um processo" (idem, p.193). Segundo Pêcheux, "vão se formando 'respostas' novas a questões que não haviam sido colocadas", processo esse no qual certos "nomes e expressões se apagam", ao passo que outros "aparecem sob o efeito de certos deslocamentos do campo, de certas intrusões 'incongruentes' de elementos 'lançados', desligados-caídos de outros lugares” (idem, p.194). E a "suposta indiferença" quanto a tais nomes não passa de mito.

Quando da interpelação, o sujeito apropria-se de saberes que, preexistentes a seu discurso, provêm do interdiscurso. A tomada de posição, condição sine qua non da produção do discurso, ocorre através de alguma destas três modalidades: identificação, contraidentificação e desidentificação, todas envolvendo uma relação entre o sujeito e o Sujeito Universal (ou forma-sujeito, organizadora dos posicionamentos possíveis) da formação discursiva no interior do qual se constitui o sujeito. A primeira modalidade concebida por Pêcheux (1975/1988), a identificação, refere uma superposição entre sujeito e Sujeito; trata-se do "bom sujeito", aquele que reproduz fielmente os saberes. Já o segundo caso, contra- 
identificação, refere uma relação tensa entre sujeito e Sujeito, uma agitação (este é um termo bem apropriado) no interior da FD. Como o nome sugere, a contra-identificação corresponde a uma tomada de posição pela qual o sujeito, ainda que conteste e/ou questione parcelas de saber da FD, ainda permanece ali inscrito, sendo chamado por Pêcheux, em decorrência disso, de "mau sujeito". Essa permanência, aliás, atesta a não-unicidade inerente à forma-sujeito. A contra-identificação permite entrever heterogeneidade na formação discursiva. Finalmente, a terceira modalidade corresponde à desidentificação, em que o sujeito desliga-se de relações com o Sujeito Universal de um campo e migra para outra FD, movimento em que se identifica com novo Sujeito a partir de nova interpelação.

Indursky (2008), fazendo de tais considerações pecheutianas a base de sua reflexão, propõe uma releitura dessas três modalidades, releitura essa decorrente do objetivo de refletir acerca da trajetória da categoria sujeito em AD. Indursky acredita que, antes de identificar-se com a forma-sujeito propriamente dita e através dela com a ideologia, o sujeito relaciona-se, na verdade, com parcelas de saber da FD. Para a autora, o fato de a forma-sujeito ser fragmentada e comportar em si a contradição autoriza que se possa considerar a existência de mais do que duas posições possíveis: há uma posição que aparece como dominante, mas há também espaço não para uma, mas para várias outras posições-sujeito "não-dominantes" em relação àquela. Depreende-se das reflexões tecidas por Indursky a possibilidade de haver diferentes posicionamentos coexistentes de contra-identificação passíveis de ser comportados pela forma-sujeito de um campo de saber, e isto em decorrência de singulares modos de relação entre sujeito e ideologia (via tomada de posição). A questão para Indursky é pensar o caso em que a movimentação de sentidos no interior da FD não chega a induzir a ruptura "radical e definitiva", antagônica mesmo, própria à desidentificação. Daí a proposta de conceber o acontecimento enunciativo, que, relacionado à contra-identificação, coloca em cena um novo modo de enunciar no interior de uma FD, modo este que opera pelo viés da tensão e do estranhamento; trata-se, pois, de um conflito interno, que ocorre em relação aos modos enunciativos de uma dada posição-sujeito (geralmente a dominante).

O novo modo de enunciar, uma vez instaurado no domínio em que irrompe, atesta o atual posicionamento que o sujeito-autor-revisor passa a assumir. Tal assunção traz a possibilidade da produção de novos sentidos não só ao campo teórico, mas à materialidade da edição revista (já que esta o representa linguístico-historicamente). Neste caso, é preciso desconstruir a edição antiga e construir a nova versão do livro numa edição dita "revista", procedimento esse que coloca em cena a tensão simultânea entre aquilo que, parafraseado (ou reproduzido ipsis litteris) permanece na mesma matriz de sentido, e aquilo que, deslocado, implica efetivamente a reformulação, ou seja, um modo totalmente outro de enunciar. Indissociavelmente, as ilusões de que "isto é meu" e "eu digo (ou reformulo) isto desta forma" caracterizam o modo pelo qual o sujeito-autor-revisor é afetado pelo jogo entre memória e esquecimento, no momento em que o texto objeto de reformulação (a edição antiga) apresenta-se a ele enquanto um "acontecimento a ler" (Pêcheux, 1983/1999).

Orlandi (2001, p.65) afirma que as versões mostram "uma relação que não é rígida nem definitiva com as formações discursivas: as margens das diferentes versões exibem difíceis limites fluidos e cambiantes na relação das formações discursivas". Pode-se deslocar isto e dizer que revelam a heterogeneidade da forma-sujeito no âmbito de uma única FD. Segundo a autora, é inerente a todo texto a possibilidade de distintas formulações e reformulações; há textos possíveis nas margens do texto. Ocorre que as diferentes versões de um texto não se dispersam isoladamente; ao contrário, formam redes de memória em relação àquilo que é dito novamente e reformulado. O novo livro, decorrente do processo de 
reformulação, constrói-se a partir de já-ditos e situa-se em relação a um dado contexto sóciohistórico que, simultaneamente, induz, constitui, marca suas condições de produção.

\section{Acontecimento enunciativo e contradição no processo discursivo em pauta}

A assunção da autoria implica uma posição do sujeito no contexto sóciohistórico (Orlandi, 2007, p.76). Atravessado por $\mathbf{n}$ discursos, o sujeito desprende-se de seu lugar de autor, ocupa o de leitor e, a partir daí, reformula o texto desde um novo posicionamento ideológico e uma nova conjuntura sócio-histórica. A função-autor é, pois, exercida a partir do lugar em que o sujeito se faz leitor de si. E o texto é reformulado sob a indissociável atuação de dois "esquecimentos" (PÊCHEUX, 1975/1988), p. 1) o sujeito não é origem absoluta do texto que produz; e 2) há outras $n$ possibilidades de (re)formular o que é dito. Nessa perspectiva, o processo discursivo aqui tomado como objeto analítico tem o seguinte estatuto: se, por um lado, ele não é inteiramente inconsciente, por outro, ele tampouco é totalmente consciente. Há, pois, jogo entre essas duas "forças", apesar da ilusão subjetiva de controle do dizer, a qual, como se sabe em $\mathrm{AD}$, domina o trabalho de autoria de todo sujeito produtor de texto (incluindo, é claro, o sujeito-autor-revisor, que produz de fato um novo texto, uma nova versão).

Admitindo que o acontecimento enunciativo, constitutivo da elaboração da edição revista, manifesta-se de diferentes modos na materialidade discursiva da edição revista, elegemos para este artigo a forma da contradição. As justificativas pela existência da nova edição viabilizam tangenciar o processo de interpelação que permite ao sujeito apropriar-se de novas parcelas de saber e, num movimento simultâneo, desapropriar-se de parcelas antigas por contra-identificação. Sendo assim, Notas do Autor e prefácios possibilitam entrever as transformações por que passou o domínio de saber (FD) no interior do qual se inscreve (e se constitui) o sujeito. Qual a relação do sujeito-autor-revisor com as distintas versões de um seu livro? É o que veremos. ${ }^{2}$ Observem-se as sequências discursivas (onde EP= edição de partida e ER= edição revista):

(SD1) EP - Este livro reúne ensaios que foram escritos sob grande tensão intelectual e moral. O golpe de Estado de 1964 não me apanhou desprevenido. Todavia, como outros intelectuais, não tive meios concretos para fazer algum tipo de oposição válida e eficaz à ditadura militar, que então se estabeleceu. Onde e quando surgiram oportunidades, procurei aproveitá-las, manifestando o meu inconformismo diante da ruptura com as pequenas e superficiais conquistas do regime democrático em nosso País. (FERNANDES, 1968, p.7). [grifos nossos]

$\mathrm{ER}-\varnothing$

(SD2) $\quad \mathrm{EP}-\varnothing$

$\mathrm{ER}-O$ texto que se segue é bastante diferente do que, escrito em 1967, figurava sob o mesmo título [...]. A razão disso é dupla: o campo da Poética não é mais hoje o que era há seis anos e eu próprio não o encaro sempre da mesma maneira. Mas um texto totalmente novo não poderia mais integrar-se em nosso projeto inicial. Preservei, portanto, a intenção geral e o quadro da primeira versão [...], modificando, contudo, o enunciado cada vez que isso se tornou necessário para prestar contas do atual estado da Poética. (TODOROV, 1976, p.7) [grifos nossos]

(SD3) $\quad \mathrm{EP}-\varnothing$

ER - Amadurecido pela leitura atenta dos teóricos da linguagem, da produção acadêmica universitária, das críticas e sugestões gentilmente formuladas por companheiros da mesma seara e da leitura demorada de nossos melhores escritores, verá facilmente o leitor que se trata aqui de um novo livro.

\footnotetext{
${ }^{2}$ Para reflexões mais consistentes, conferir SILVA, 2009.
} 
Dificilmente haverá seção da Moderna Gramática Portuguesa que não tenha passado por uma consciente atualização e enriquecimento [...] (BECHARA, 2005, p.19) [grifos nossos]

Analisemos a SD1, do Prefácio de Sociedade de Classes $e$ Subdesenvolvimento, de Florestan Fernandes, Prefácio esse que figura apenas em EP. O apagamento, na ER, do Prefácio da edição anterior (bem como a inexistência de outro que lhe substitua) caracteriza o apagamento de explicações acerca das condições de produção de cada um dos ensaios que compõem o livro. Relegam-se, pois, ao silêncio a tensão moral/intelectual, o contato com certas pessoas, o grau de recepção em eventos, os objetivos básicos. Diante de tão curto intervalo temporal (1968-1972) entre uma edição e outra, interessa-nos lembrar que EP foi publicada no mesmo ano em que ocorreu a imposição do AI5, o qual, marcando o período mais cruel do regime militar, estendeu-se até 1979. Como se vê, também ER não escapou de ser produzida sob a vigência do militarismo, o qual, alegando livrar da corrupção/ subversão o Brasil, promoveu indigestos episódios sobretudo no meio acadêmico, onde muitos professores, técnicos, alunos tiveram suas carreiras violentadas, se não estraçalhadas pelo regime ditatorial. Diante de tal contexto, é bastante compreensível que um Prefácio do porte daquele de Fernandes seja apagado em nome de um "silêncio" político favorável à publicação dos ensaios comportados pelo livro em pauta.

Passando agora às SDs 2 e 3, temos em ambas o caso em que o sujeito-autorrevisor pontua claramente sua contra-identificação com o posicionamento que assumira na $\mathrm{EP}$, e, com isto, coloca de modo explícito a nova conjuntura. Nessas duas SDs, figura o alerta de que o texto de ER é, na verdade, outro, diferente daquele da EP e assumido como algo que é, de fato, uma reelaboração. Seguindo a ordem de apresentação das sequências discursivas, falemos primeiramente da SD2, cujas formulações provêm da "Nota sobre esta edição", escrita por Todorov para a edição revista de Estruturalismo e Poética (1976).

É dominante, nessa SD, o lugar de entremeio de um sujeito-autor-revisor oscilante entre dizer do mesmo e dizer do outro, na medida em que há um limite para a diferença, senão o texto já não poderia inscrever-se num "projeto inicial" semelhante ao da versão anterior (pensar a Poética em sua relação com o Estruturalismo). Veja-se a formulação de Todorov (1976): “o campo da Poética não é mais hoje o que era há seis anos e eu próprio não o encaro sempre da mesma maneira" (cf.SD2). Constata-se, a partir daí, o fato de que antes mesmo de revelar um compromisso social com o sujeito-leitor e com a produção de conhecimento, o processo de reformulação sinaliza o compromisso do sujeito-autor com sua própria condição. Isto porque tal sujeito só se reconhece como autor se aquilo que ele produz lhe aparece como algo de que se possa enunciar: "faz sentido publicar isso"; ora, EP já não se enquadra mais neste perfil. Já Bechara parece assumir o posicionamento que categoricamente situa a edição revista como um livro verdadeiramente outro. Observe-se a SD3, cujas formulações figuram no Prefácio escrito por Bechara à $37^{a}$ edição (a edição revista, justamente) de sua Moderna Gramática Portuguesa (2005). A afirmação de que se trata efetivamente de um outro livro em nada semelhante à edição anterior (como se lê em "verá facilmente o leitor que se trata aqui de um novo livro") permite flagrar mais facilmente o novo acontecimento enunciativo que se instaura no interior da FD.

A análise dos distintos posicionamentos assumidos pelos sujeitos viabiliza alcançar o funcionamento da heterogênea forma-sujeito de cada uma das formações discursivas em questão (quais sejam: Sociologia, Poética e Gramática, respectivamente), no modo como esse funcionamento se vê subordinado a condições de ordem sócio-histórica (ideológica, mas também jurídica e mesmo econômica, para citar alguns fatores). Vê-se que Prefácios e Notas do Autor constituem espaços privilegiados para observação das diferentes relações entre sujeitos, livros, saberes. Orlandi, por exemplo, ao examinar as reedições sobre 
o "descobrimento" do Brasil elaboradas por outros sujeitos que não os autores das obras "originais", afirma que tais reedições comportam, majoritariamente, "um aparelho crítico, composto de prefácios e notas que remetem ao fio dos textos originais" (1990, p.102). Acreditando que notas e prefácios constituem um discurso paralelo e posterior, sob a forma de suplementos ou "acréscimos marginais" ao texto, Orlandi (idem) pontua que "cada reedição resulta em um outro discurso que trabalha os limites (o início e as margens) do texto, ou melhor, da formação discursiva constituída pelo discurso sobre as descobertas". E mais: "Dada a mudança das condições de produção [a saber: locutores, leitores, situação científica/religiosa/política] os comentários, através da acomodação científica, restabelecem o equilíbrio (o mesmo), produzindo uma correção de perspectiva" (idem, p.116).

Avançando, o fato é que o sujeito não tem como negar que anteriormente construiu de modo diverso o livro que ali está, e por aí se instaura uma contradição no processo de reformular o texto. Isto porque se por um lado é necessária a evidência ideológica de um novo texto homogêneo, por outro é igualmente necessário desconstruir o efeito-texto da edição de partida (EP) na edição revista (ER) e, ao fazer isto, o sujeito, consciente ou não disso, acaba por igualmente fazer esvaecer o efeito-texto da ER. Como lembra Gallo (1992, p.58) sobre este aspecto do funcionamento da autoria, a assunção da autoria pelo sujeito “consiste, em última análise, na assunção da 'construção' de um 'sentido' e de um 'fecho' organizadores de todo o texto". Acreditamos que, embora as reflexões de Gallo tenham sido construídas sobre análises de produções textuais de alunos, podemos deslocá-las para cá, visto que tratam do funcionamento do efeito-autor sobre um texto. Falávamos a respeito dos Prefácios e Notas do Autor, e é precisamente aqui que gostaríamos de ir adiante e colocar indagações: ainda que apareçam no início de livros, não serão os prefácios e as notas do Autor, também eles, uma espécie de efeito-fecho de um livro que já aparece ao sujeito como ilusoriamente fechado? Emerge então a dialética entre mesmo e outro, com a pergunta: o que costuma fazer o prefácio da EP na ER (exceto no caso de apagamento já referido)? Por que a repetição e, frequentemente, a existência de dois prefácios distintos? Ora, considera-se, no âmbito da formação social, que, embora seja uma outra edição, o livro, enquanto livro $\mathrm{X}$ imputado a um autor $\mathrm{Y}$, permanece sendo o mesmo. Nessa direção, a grande problemática colocada pelo processo discursivo aqui investigado é: até onde se pode, ou não, ultrapassar os limites da "identidade" de um livro? O que pensar da edição revista, uma vez instaurada a relação entre versões?

\section{A relação entre versões observada à luz da Análise do Discurso: uma presença "à la Clémentis"?}

O processo discursivo aqui tomado como objeto comporta constitutivamente em seu funcionamento a sucessão, a simultaneidade e a permanência. Há uma dialética entre, de um lado, a sucessão de certos saberes e tomadas de posição (os quais perdem seu posto em prol da hegemonia de saberes e posicionamentos emergentes), e, de outro, a simultaneidade de sentidos, logo, também dos posicionamentos que os instauram. Tal dialética converge em direção à permanência típica da ordem do discurso. Ora, segundo Pêcheux (1969/1993), todo discurso é parte de um processo discursivo contínuo e mais amplo. Há, portanto, um processo único (qual seja, a própria ordem do discurso) no interior do qual se inscrevem, em diferentes condições sócio-históricas, EP e ER.

A ordem do discurso é em si mesma inapreensível e só pode ser tomada através de objetos simbólicos (os livros, no caso) que, ao recortarem-na sócio-historicamente e materializarem-na linguisticamente, a trazem como um elemento constitutivo de suas 
próprias existências. Nessa perspectiva, não são propriamente as edições que se sucedem (aliás, elas coexistem, apesar da ilusão de que uma invalida a outra); o que ocorre é a sucessão de uma dada relação "sujeito-saber-ideologia na conjuntura $X$ " por uma outra relação "sujeito-saber-ideologia na conjuntura Y". Diante disso, a permanência assegura a reprodução do "mesmo", enfim, sua repetição, pois mudar totalmente os saberes seria trocá-los de formação discursiva, o que é inconcebível, pois se ocorresse, estar-se-ia diante da desidentificação própria a uma ruptura epistemológica (PÊCHEUX, 1975/1988), e não de um redimensionamento interno (reformulação teórica). Embora não seja radical como a ruptura, a reformulação também se refere a um "ponto sem regresso" (PÊCHEUX; FICHANT, 1969/1971), a partir do qual se pretende instaurar a impossibilidade de retomada de certas parcelas de saber precedentes. No entanto, é por haver ainda algo de permanente - o repetível - que podem surgir diferentes modos de enunciar, sem que com isto se desfigure a relação do sujeito com o domínio de saber. A descontinuidade com certos modos de enunciar, por sua vez, instaurada pela sucessão acima referida, sinaliza a dispersão pelo jogo entre memória e esquecimento.

Tomado na teia das contradições históricas do campo em que se constitui, o sujeito entra num jogo de repetir/deslocar/esquecer, procedimentos estes aos quais cabe a metáfora topológica do nó, já que eles formam um verdadeiro nó na materialidade textual da edição revista. Considerar a contradição, instaurada no interior de um campo pelo viés da contra-identificação subjetiva, abre espaço para a emergência do outro, paradoxalmente mostrado e escondido sob a materialidade da edição revista. À moda do episódio de Clémentis - como Courtine (1982/1999) resgata de Kundera -, por meio do qual Clémentis, ainda que apagado da fotografia, faz-se nesta ainda presente memorial e materialmente através de seu chapéu, que emprestara a Gottwald, da mesma forma a edição de partida faz-se assim presente apesar da pretensão de que possa ser apagada em prol da edição revista. Nesta, aquela se mostra presente, mas transformada; ou ainda, presente pela necessidade de que se a esqueça: deve-se trazê-la à tona para enunciar que já não funciona mais como algo que "faz sentido ser publicado e academicamente mencionado"; enfim, para justificar, antes da substituição, a diferença e a primazia da nova.

A edição revista desconstrói a unidade aparente da edição de partida; ao fazêlo atestando a incompletude desta, acaba por acentuar sua própria. De fato, o livro desdobrase tecendo um comentário de si e de seu avesso, isto é, de si enquanto "edição revista" e daquele que ele era, emergindo assim a dialética entre o que ele é e o que ele não é mais, entre o que ele pode e o que não pode prosseguir dizendo, engendrando-se por aí um embate entre as diferentes posições ideológicas que, por sua vez, revelam a contradição inerente ao "lugar discursivo" de onde enuncia o sujeito. O ponto essencial que autoriza a referir o processo discursivo de reformulação de livros como radicalmente contraditório, reside em que não se trata de opor uma edição $\mathrm{X}$ à sua edição revista $\mathrm{Y}$, mas de fazer equivaler, como semelhantes de modo geral (ou seja, no "pensamento diretor"), duas edições internamente distintas. A forma (título) permanece materialmente repetida; porém, seu sentido é outro e, por isso, defendemos que o livro é outro. Tomemos um exemplo: Moderna Gramática Portuguesa. O que significa Moderna em 1987 já não vale para 2005. Tampouco Gramática tem sentido fixo diante dos avanços dos estudos linguísticos. Por trás da repetição aparentemente transparente do título, esconde-se a opacidade do discurso; o confronto entre enunciável e não-mais-enunciável; o fantasma do outro a espreitar o um; a errância de sentidos deslizantesdesviados-esquecidos. Esquecimento imbuído de memória.

Tudo quanto precede atesta/justifica nossa crença em que não há possibilidade de enunciar que os livros sejam efetivamente equivalentes, mas, isto sim, se pode e se deve 
pontuar sua irrepetibilidade. Ora, reforça isto o fato de as condições de produção de cada uma das edições serem singulares, logo, irrepetíveis.

\section{Para concluir}

O trajeto percorrido para exame do funcionamento da autoria no objeto de reflexão apontou que a grande problemática colocada em cena pelo processo discursivo examinado reside na identidade da edição revista, edição esta que, como vimos, não tem de idêntico à anterior nem sequer o título, já que este, ainda que repetido ipsis litteris, significa de um modo radicalmente outro.

Referir a reformulação enquanto processo discursivo autorizou a inscrever a edição revista, assim como a edição de partida, na historicidade da ordem do discurso e, deste modo, pensar os redimensionamentos internos de domínios de saber. Nessa direção, o acontecimento enunciativo - conceito concebido por Indursky (2008) - emergiu como uma noção-pivô da reflexão, visto que não só ele instaura o processo discursivo examinado, mas, igualmente, fomenta a continuidade do campo de conhecimento no interior do qual surge; ele, além disso, instaura novas filiações de sentido e com isso reconfigura as redes de memória, fazendo trabalhar as fronteiras do enunciável de uma dada formação discursiva.

Sendo necessário encerrar a presente discussão, parece apropriado trazer o que diz Lopes (1997, p.46): "Certamente, um livro de ciência não vale pelo que ele fixa, mas pelo que ele põe em movimento; não pelo que ele colhe, mas pelo que semeia". E continua, então, o referido autor: "Sabemos todos bem que o futuro é caprichoso e se compraz em entortar hoje o que ontem pareceu correto e em endireitar amanhã o que hoje nossa miopia entorta" (ibid.). A produção de conhecimento, sendo parte de um processo discursivo mais amplo, existe em constante mutação, prova incontestável de que, antes de outra coisa, ela envolve sujeitos e prática de linguagem, enfim, palavras em movimento, discursos.

\section{Referências bibliográficas}

BECHARA, E. Moderna Gramática Portuguesa. 31.ed. São Paulo: Companhia Editora Nacional, 1987.

Moderna Gramática Portuguesa. 37.ed.rev. e ampl., 15.reimpr. Rio de Janeiro: Lucerna, 2005.

COURTINE, J-J. O chapéu de Clémentis. Trad. por Marne R. Rodrigues. In: INDURSKY, F.; LEANDRO FERREIRA, M.C. (Orgs.). Os múltiplos territórios da Análise do Discurso. Porto Alegre: Sagra-Luzzatto, 1999. p.15-22. (Trad. de: La toque de Clémentis, 1982)

FERNANDES, F. Sociedade de classes e subdesenvolvimento. Rio de Janeiro: Zahar, 1968.

Sociedade de classes e subdesenvolvimento. 2.ed.rev. Rio de Janeiro: Zahar, 1972.

GALLO, S. Discurso da Escrita e Ensino. Campinas: Unicamp, 1992.

INDURSKY, F. Da heterogeneidade do discurso à heterogeneidade do texto e suas implicações no processo da leitura. In: ERNST-PEREIRA, A.; FUNCK, S.B. (Orgs.). A leitura e a escrita como práticas discursivas. Pelotas: Educat, 2001. p.27-42.

. Unicidade, desdobramento, fragmentação: a trajetória da noção de sujeito em Análise do Discurso. In: MITTMANN, S.; CAZARIN, E.; GRIGOLETTO, E. (Orgs.) Práticas discursivas e identitárias - Sujeito e língua. Porto Alegre: UFRGS, 2008. p.9-33. LOPES, E. A Identidade e a Diferença - Raízes Históricas das Teorias Estruturais da Narrativa. São Paulo: EDUSP, 1997. 
ORLANDI, E.P. Terra à vista - Discurso do confronto: Velho e Novo Mundo. São Paulo: Cortez; Campinas: Unicamp, 1990.

Discurso e texto - Formulação e circulação dos sentidos. Campinas: Pontes, 2001. Análise de Discurso: princípios \& procedimentos. 7.ed. Campinas: Pontes, 2007. PÊCHEUX, M. Semântica e discurso: uma crítica à afirmação do óbvio. Trad. por Eni P. Orlandi [et al.]. Campinas: Unicamp, 1988. (Trad. de: Les vérités de la Palice, 1975) . Análise automática do discurso. Trad. por Eni P. Orlandi. In: GADET, F.; HAK, T. (Orgs.). Por uma análise automática do discurso: uma introdução à obra de Michel Pêcheux. 2.ed. Campinas: Unicamp, 1993. p.61-161. (Trad. de: Analyse automatique du discours, 1969)

Papel da memória. In: ACHARD, P. [et al.]. Papel da Memória. Trad. e introd. de José H. Nunes. Campinas: Pontes, 1999. p.49-57. (Trad.de: Rôle de la mémoire, 1983)

; FICHANT, M. Sobre a história das ciências. Trad. por Francisco Bairrão. Lisboa: Estampa, 1971. (Trad. de: Sur l'histoire des sciences, 1969)

SILVA, A.P.L.V. Entretextualidade nas fronteiras do enunciável: um olhar sobre o processo discursivo de reformulação de livros. Dissertação de Mestrado. Porto Alegre: UFRGS, 2009.

TODOROV, T. Estruturalismo e Poética. Trad. por José P. Paes. São Paulo: Cultrix, 1970. Estruturalismo e Poética. 4.ed. rev. e ampl. cf. ed. franc. de 1973. Trad. por José P. Paes e Frederico P. de Barros. São Paulo: Cultrix, 1976.

ZANDWAIS, A. Relações entre a Filosofia da Práxis e a Filosofia da Linguagem sob a ótica de Mikhail Bakhtin: um discurso fundador. In: (Org.). Mikhail Bakhtin Contribuições para a Filosofia da Linguagem e Estudos Discursivos. Porto Alegre: SagraLuzzatto, 2005. p.83-100. (Col. Ensaios, v.20) 